\title{
Evidence for the Rapid Conversion of Stephacidin B into the Electrophilic Monomer Avrainvillamide in Cell Culture
}

\author{
Jeremy E. Wulff, Seth B. Herzon, Romain Siegrist, and Andrew G. Myers \\ Department of Chemistry and Chemical Biology, Harvard University, Cambridge, Massachusetts \\ 02138
}

\begin{abstract}

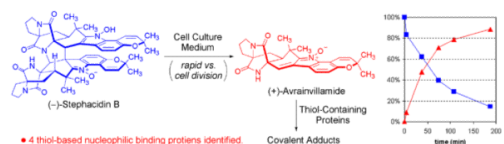

We report that the dimeric alkaloid stephacidin B (1) and the monomeric alkaloid avrainvillamide (2) function equivalently within experimental error to inhibit the growth of four different cultured human cancer cell lines. We also show that the proportion of the monomer greatly outweighs that of the dimer in the medium of incubation, and that the half-life for the transformation of $\mathbf{1}$ to $\mathbf{2}$ is short relative to the half-life of cell division. Finally, using a monomer-based affinity reagent, we provide evidence that the monomer (2) interacts with intracellular thiol-containing proteins, likely by covalent modification.
\end{abstract}

Here we report that the dimeric alkaloid stephacidin B (1) and the monomeric alkaloid avrainvillamide (2) function equivalently within experimental error to inhibit the growth of four different cultured human cancer cell lines. We also show that the proportion of the monomer greatly outweighs that of the dimer in the medium of incubation, and that the halflife for the transformation of $\mathbf{1}$ to $\mathbf{2}$ is short relative to the half-life of cell division. Finally, using a monomer-based affinity reagent, we provide evidence that the monomer (2) interacts with intracellular thiol-containing proteins, likely by covalent modification.
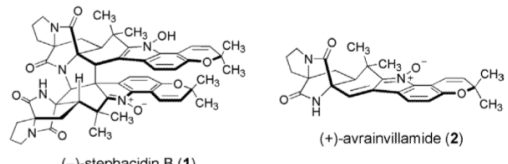

Stephacidin B (1), isolated in 2001 from a culture broth of Aspergillus ochraceus WC76466, was reported to inhibit the growth of a testosterone-dependant prostate cancer cell line (LNCaP) at nanomolar concentrations, ${ }^{1}$ while avrainvillamide (2), isolated in 2000 from a culture broth of Aspergillus sp. CNC358, was reported to inhibit the growth of two breast cancer cell lines ( $\beta$ T-549 and T-47D) as well as a metastatic malignant melanoma of the lung (MALME-3M) ${ }^{2}$ It was recognized that stephacidin B (1) was potentially the product of dimerization of avrainvillamide (2), ${ }^{1,3}$ and some support for this hypothesis was presented in 2005, when two groups, having reported laboratory synthetic routes to $\mathbf{1}$ and $\mathbf{2}$, described mild, albeit abiological conditions for their interconversion (upon standing on silica gel or in

*myers@chemistry.harvard.edu .

Supporting Information Available: Preparation of $3-6$ and details of affinity-isolations and enzymatic assays. This material is available free of charge via the Internet at http://pubs.acs.org. 
the presence of triethylamine in acetonitrile). ${ }^{4,5}$ To our knowledge, side-by-side comparisons of $\mathbf{1}$ and $\mathbf{2}$ in antiproliferative assays have not been reported, nor have the rates of interconversion of $\mathbf{1}$ and $\mathbf{2}$ been established in a physiologically relevant setting.

We first evaluated the growth-inhibitory properties of $\mathbf{1}$ and $\mathbf{2}$ in parallel, in the four cultured cancer cell lines for which potent inhibition had been reported for either compound alone (Table 1). In the same study, we measured the activities of the pure enantiomers of $\mathbf{1}$ and $\mathbf{2}$ (ent-1 and ent-2, respectively). All four compounds tested were synthesized by a stereodefined route. ${ }^{4}$ We observed that $\mathbf{1}$ and $\mathbf{2}$ exhibited a range of growth-inhibitory potencies $\left(\mathrm{GI}_{50}\right.$ values) from $91-621 \mathrm{nM}$, depending on the cell line (see Supporting Information). Notably, ent-1 and ent-2 were hardly inactive, and in the $\beta T-549$ cell line in particular, the unnatural enantiomers were only $\sim 2$-fold less potent inhibitors of growth. In all cell lines, and in both enantiomeric series, the dimeric alkaloids $((+)-$ or $(-)-\mathbf{1})$ were approximately equipotent to the monomeric alkaloids $((-)-$ or $(+)-2)$ in the corresponding series when corrected for stoichiometry (i.e., solutions of $\mathbf{1}$ were twice as potent as equimolar solutions of $\mathbf{2}$ ).

We followed the transformation of the dimeric alkaloid (+)-1 to the monomeric alkaloid $(-)-2$ in cell culture medium (10\% fetal bovine serum in RPMI 1640, ${ }^{6}$ containing 6\% DMSO to solubilize the alkaloids) by HPLC analysis (Figure 1A), and found that $(+)-\mathbf{1}$ was converted to (-)-2 with a half-life of $\sim 50 \mathrm{~min}$ at $23{ }^{\circ} \mathrm{C}$, and $\sim 10 \mathrm{~min}$ at $37{ }^{\circ} \mathrm{C} .{ }^{7}$ Given these data, and the time necessary to prepare solutions of the four compounds in cell culture medium, serially dilute the solutions, and then add the diluted solutions to the cells ( $\sim 3 \mathrm{~h}$ at $23^{\circ} \mathrm{C}$ ), it is unlikely that there was a substantial fraction of the dimeric alkaloid present by the time drug effects were first observed (morphological changes in the growing cells were evident within hours at $37^{\circ} \mathrm{C}$; final measurements of cell viability were performed after $48 \mathrm{~h}$ at $\left.37^{\circ} \mathrm{C}\right)$.

Further evidence that the growth-inhibitory activity of the dimeric alkaloid stephacidin B (1) arises from the monomeric alkaloid avrainvillamide (2) comes from our discovery that a number of structurally simpler analogs, incapable of dimerization, exhibit considerable potency in antiproliferative assays. Two representative examples from several that we have identified are the 3 -alkylidene- $3 H$-indole 1 -oxides 3 and $\mathbf{4}$, both micromolar inhibitors of $\mathrm{LNCaP}$ and T-47D cell lines (Figure 1B). Compound $\mathbf{3}$, first prepared in a synthetic model study ${ }^{8}$ is comparable in activity in T-47D cells to the unnatural enantiomer of avrainvillamide ((-)-2), and is only one order of magnitude less potent than natural avrainvillamide (+)-2. ${ }^{9}$ The data support the proposal that $\mathbf{2}$ is the biologically active form of $\mathbf{1}$, but only insofar as it is true that $\mathbf{3}$ and $\mathbf{4}$ function by the same mechanism as $\mathbf{1}$ and $\mathbf{2}$. Some evidence that $\mathbf{3}$ and $\mathbf{4}$ bind to, and perhaps target, at least a subset of proteins that interact with $\mathbf{1}$ and $\mathbf{2}$ was gained from affinity isolation experiments using the reagent $\mathbf{5}$, synthesized (as a 1:1 mixture of diastereomers, and a 5.5:1 mixture of E:Z isomers; see Supporting Information) to explore the hypothesis that the antiproliferative agents $\mathbf{1}-\mathbf{4}$ might covalently modify nucleophilic residues of one or more proteins by addition to the electrophilic 3-alkylidene-3 $\mathrm{H}$-indole 1 -oxide function of these compounds. ${ }^{4}$

To identify potential binding proteins, an $\mathrm{LNCaP}$ cell lysate was treated with the activitybased probe ${ }^{10,11} \mathbf{5}$ (Figure 2), in the presence or absence of a 20 -fold excess of compounds 2 or $\mathbf{3}$ as competitive binders. Streptavidin-agarose was added, the resin was removed by centrifugation, then was washed, and Laemmli buffer was added to liberate any bound proteins. Following separation by SDS-PAGE, protein bands were excised and sequenced by LC-MS/MS. Among several candidate proteins identified in this manner (see Supporting Information), 4 have thus far been confirmed by Western-blotting (Figure 2). 
The results of our study suggest that both (+)-avrainvillamide (2) and the analog $\mathbf{3}$ interact with a variety of cysteine-containing proteins in the cell lysate, including heat-shock protein 60 (HSP60), exportin 1 (XPO1), glutathione reductase (GR) and peroxiredoxin 1 (PRX1). $\mathrm{GR}^{12}$ and PRX1 ${ }^{13}$ are homodimeric oxidoreductase enzymes, each with 4 active-site cysteine residues (distributed between two active sites). HSP60 and XPO1 do not have cysteine in their active sites, but both have accessible, nucleophilic cysteine residues that are known to be alkylated by other electrophilic inhibitors. ${ }^{14,15}$

Interestingly, while co-incubation with $\mathbf{2}$ or $\mathbf{3}$ led to a reduction in the amounts of HSP60 and XPO1 bound to probe 5 (compare lane 3 of Figure 2 with lane 2, or compare lane 5 with lane 4) the same conditions led to a marked increase in the binding of GR and PRX1 to 5. This presumably relates to the fact that GR and PRX1 have dual active sites, which may exhibit cooperative binding. Protein binding to 5 was blocked in the presence of iodoacetamide $(10 \mathrm{mM})$, lending support to the hypothesis that $\mathbf{2}-\mathbf{5}$ may function by alkylating cysteine residues. ${ }^{16}$

In enzymatic assays (+)-avrainvillamide (2) reversibly inhibited human GR activity in $\mathrm{LNCaP}$ cell lysate with an $\mathrm{IC}_{50}$ value of $\sim 125 \mu \mathrm{M}$ (see Supporting Information). The inhibitory activity decreased with the addition of glutathione disulfide, the natural substrate for GR, consistent with active-site inhibition by 2 . (+)-Avrainvillamide (2) was a poor inhibitor of yeast GR.

Our results suggest that the antiproliferative activity of stephacidin B (1) arises from its prior dissociation to form avrainvillamide (2), which may then bind to one or more proteins with nucleophilic cysteine residues, likely by covalent modification. The four specific proteins identified here may or may not be important cellular targets for $\mathbf{2}$ (the relatively weak inhibition of GR by 2 makes this protein an unlikely candidate); further experiments are necessary. It is interesting to note that while our early model studies showed that both alcohols and thiols can add reversibly to the unsaturated nitrone function of $\mathbf{2}$ and $\mathbf{3},{ }^{4,8}$ thus far only cysteine-based nucleophilic proteins have been identified as binding partners in our our affinity isolation studies.

\section{Supplementary Material}

Refer to Web version on PubMed Central for supplementary material.

\section{Acknowledgments}

We are indebted to Ross Tomaino for protein sequencing, and to the Bauer Center for Genomics Research for the use of equipment. We gratefully acknowledge NSERC (J.E.W.), NSF (S.B.H.), and SNSF (R.S.) for fellowship support. This work was supported by a grant from the NIH.

\section{References}

(1). (a) Qian-Cutrone, J.; Krampitz, KD.; Shu, Y-Z.; Chang, L-P.; Lowe, SE. Stephacidin Antitumor Antibiotics. US Patent. 2001. 6,291,461(b) Qian-Cutrone J, Huang S, Shu Y-Z, Vyas D, Fairchild C, Menendez A, Krampitz K, Dalterio R, Klohr SE, Gao Q. J. Am. Chem. Soc. 2002; 124:14556-14557. [PubMed: 12465964]

(2). (a)Fenical W, Jensen PR, Cheng XC. Avrainvillamide, a Cytotoxic Marine Natural Product, and Derivatives Thereof. U.S. Patent. 20006,066,635 (b) Sugie Y, Hirai H, Inagaki T, Ishiguro M, Kim Y-S, Kojima Y, Sakakibara T, Sakemi S, Sugiura A, Suzuki Y, Brennan L, Duignan J, Huang LH, Sutcliffe J, Kojima N. J. Antibiot. 2001; 54:911-916. [PubMed: 11827033]

(3). von Nussbaum F. Angew. Chem. Int. Ed. Engl. 2003; 42:3068-3071. [PubMed: 12866092]

(4). Herzon SB, Myers AG. J. Am. Chem. Soc. 2005; 127:5342-5344. [PubMed: 15826171] 
(5). (a) Baran PS, Guerrero CA, Hafensteiner BD, Ambhaikar NB. Angew. Chem. Int. Ed. 2005; 44:3892-3895.(b) Baran PS, Hafensteiner BD, Ambhaikar NB, Guerrero CA, Gallagher JD. J. Am. Chem. Soc. 2006; 128:8678-8693. [PubMed: 16802835]

(6). Roswell Park Memorial Institute culture medium, series 1640 was purchased from ATCC. For formulation, see: Moore GE, Gerner RE, Franklin HA. JAMA. 1967; 199:519-524. [PubMed: 4960081]

(7). This experiment employed the unnatural enantiomers ((+)-1 and (-)-2), which we had synthesized first.

(8). Myers AG, Herzon SB. J. Am. Chem. Soc. 2003; 125:12080-12081. [PubMed: 14518979]

(9). Structural analogs were evaluated using a slightly different method than that used for the data in Table 1 (see Supporting Information). In this assay, the $\mathrm{GI}_{50}$ for (+)-2 was $330 \mathrm{nM}$ vs. LNCaP and $420 \mathrm{nM}$ vs. T-47D.

(10). Bogyo M, Baruch A, Jeffery DA, Greenbaum D, Borodovsky A, Ovaa h. Kessler B. Curr. Prot. Protein Science. 2004; 21:17.1.

(11). (a) Liu Y, Patricelli MP, Cravatt BF. Proc. Natl. Acad. Sci. U.S.A. 1999; 96:14694-14699. [PubMed: 10611275] (b) Kidd D, Liu Y, Cravatt BF. Biochemistry. 2001; 40:4005-4015. [PubMed: 11300781]

(12). (a) Karplus PA, Schulz GE. J. Mol. Biol. 1987; 195:701-729. [PubMed: 3656429] (b) Becker K, Savvides SN, Keese M, Schirmer RH, Karplus PA. Nature Struct. Biol. 1998; 5:267-271. [PubMed: 9546215]

(13). Wood ZA, Schröder E, Harris JR, Poole LB. Trends in Biochem. Sci. 2003; 28:32-40. [PubMed: 12517450]

(14). (a) Nagumo Y, Kakeya H, Shoji M, Hayashi Y, Dohmae N, Osada H. Biochem. J. 2005; 387:835-840. [PubMed: 15603555] (b) Nagumo Y, Kakeya H, Yamaguchi J, Uno T, Shoji M, Hayashi Y, Osada H. Bioorg. Med. Chem. Lett. 2004; 14:4425-4429. [PubMed: 15357965]

(15). Kudo N, Matsumori N, Taoka H, Fujiwara D, Schreiner EP, Wolff B, Yoshida M, Horinouchi S. Proc. Natl. Acad. Sci. U.S.A. 1999; 96:9112-9117. [PubMed: 10430904]

(16). Control experiments (lanes $6-8$ of Figure 2) with compounds lacking either the biotin moiety (2 or 3) or the 3-alkylidene-3H-indole 1-oxide function (6) did not afford detectable quantities of protein in subsequent Western-blot analyses. 
A

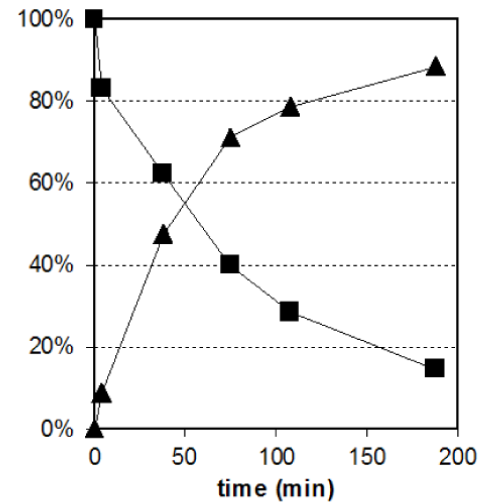

- $\%(+)$-stephacidin B (ent-1)
B

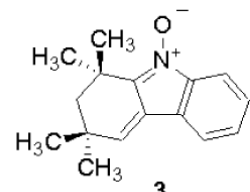

$\mathrm{GI}_{50}=4.2 \mu \mathrm{M}$ vs. $\mathrm{LNCaP}$

$1.4 \mu \mathrm{M}$ vs. T-47D

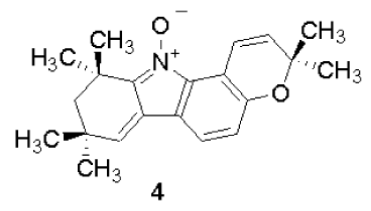

$\mathrm{GI}_{50}=5.2 \mu \mathrm{M}$ vs. LNCaP $8.4 \mu \mathrm{M}$ vs. T-47D

Figure 1.

(A) Retro-dimerization of (+)-stephacidin B (ent-1) to form (-)-avrainvillamide (ent-2) in cell culture medium containing $6 \%$ DMSO at $23{ }^{\circ} \mathrm{C}$. (B) Structures and activities of simplified avrainvillamide analogs. 


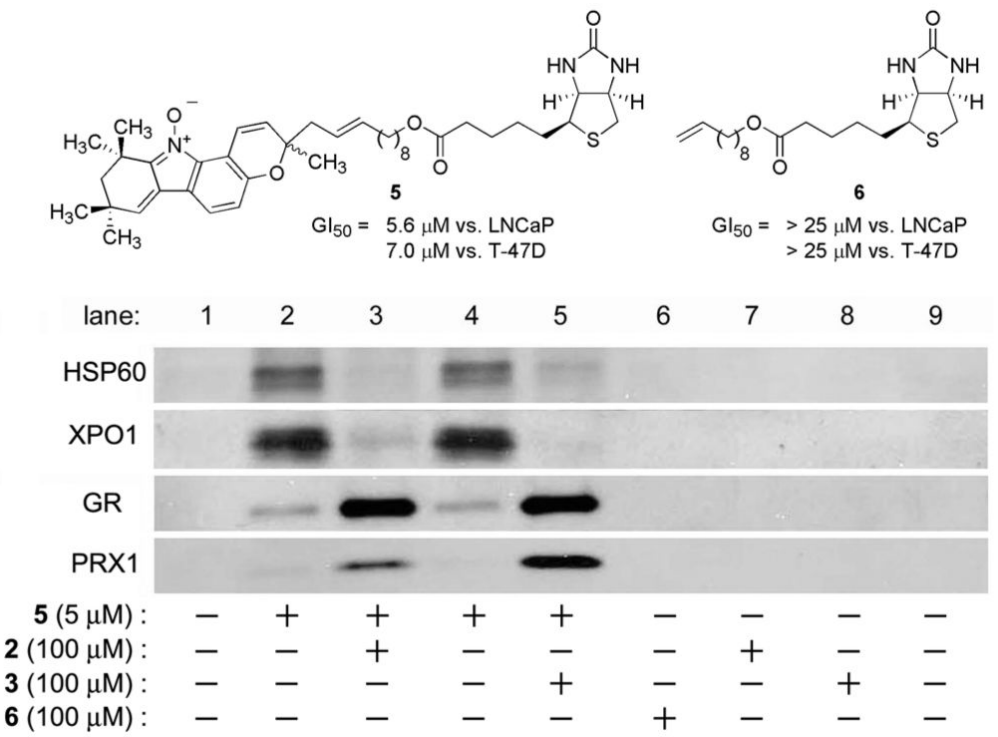

Figure 2.

Western blot detection following affinity-isolations of four cysteine-containing proteins with probe $\mathbf{5}$, in the absence and presence of competitors (+)-avrainvillamide (2) and structural analog 3 . 
Table 1

Measured $\mathrm{GI}_{50}$ Values for $\mathbf{1}$ and $\mathbf{2}^{a}$

\begin{tabular}{ccccc}
\hline & \multicolumn{2}{c}{ natural enantiomer } & \multicolumn{2}{c}{ unnatural enantiomer } \\
\hline cell line & $\mathbf{1}$ & $\mathbf{2}$ & ent-1 & ent-2 \\
\hline \multirow{2}{*}{ LNCaP } & $135 \mathrm{nM}$ & $241 \mathrm{nM}$ & $952 \mathrm{nM}$ & $1514 \mathrm{nM}$ \\
& $(40-231)$ & $(159-323)$ & $(638-1266)$ & $(1243-1786)$ \\
BT-549 & $346 \mathrm{nM}$ & $621 \mathrm{nM}$ & $550 \mathrm{nM}$ & $786 \mathrm{nM}$ \\
& $(321-372)$ & $(548-694)$ & $(488-611)$ & $(717-855)$ \\
T-47D & $91 \mathrm{nM}$ & $205 \mathrm{nM}$ & $942 \mathrm{nM}$ & $1485 \mathrm{nM}$ \\
& $(30-152)$ & $(110-299)$ & $(583-1301)$ & $(1305-1665)$ \\
MALME & $289 \mathrm{nM}$ & $406 \mathrm{nM}$ & $987 \mathrm{nM}$ & $1854 \mathrm{nM}$ \\
$-3 \mathrm{M}$ & $(108-469)$ & $(206-607)$ & $(727-1247)$ & $(1750-1957)$ \\
\hline
\end{tabular}

${ }^{a}$ Values in parentheses reflect the upper and lower limits for a $90 \%$ confidence interval. The XLfit 4 software package was used for curve-fitting and estimation of confidence intervals. 